\title{
COVID-19 reinforces the need to improve sepsis care resources in Africa
}

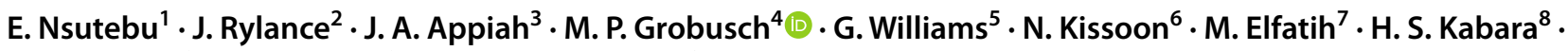 \\ K. M. Osman ${ }^{9} \cdot$ K. Reinhart ${ }^{10} \cdot$ M. Mer ${ }^{11} \cdot$ S. Jacob ${ }^{12}$
}

Received: 19 October 2020 / Accepted: 17 December 2020 / Published online: 2 January 2021

(c) Springer-Verlag GmbH, DE part of Springer Nature 2021

\section{To the Editor,}

Globally, the number of COVID-19 cases and deaths continues to rise. In Africa, over 2.2 million COVID-19 cases have been reported with over 53000 deaths as of 5 December, 2020. At that time, with the 16th highest number of cases globally ( $~ 805,000$ cases) resulting in over 22,000 deaths, South Africa is the most affected country on the continent, followed by Morocco, Egypt, Ethiopia, Tunisia, Kenya, and Algeria [1, 2]. Overall, at the time of writing, these figures are lower than initially predicted for Africa, and fewer per-population than in Europe, Asia and North and South America [3].

The reason for the lower recorded burden across Africa is yet to be fully elucidated. Sixty percent of Africans are under 25 years old, and might evade the risk of disease and death associated with increased age or comorbidities [4, 5]. Lower testing capacity, in some countries, may result in under-diagnosis. Whether or not these factors or others, such as genetic factors or immune priming from exposure to other

M. P. Grobusch

m.p.grobusch@amsterdamumc.nl

1 Infectious Disease Division, Sheikh Shakhbout Medical City, Abu Dhabi, UAE

2 Liverpool School of Tropical Medicine, Malawi-Liverpool Wellcome Trust, Liverpool, UK

3 Paediatric Unit, Komfo Anokye Teaching Hospital, Kumasi, Ghana

4 Department of Infectious Diseases, Center of Tropical Medicine and Travel Medicine, Amsterdam University Medical Centres, Location AMC, University of Amsterdam, Amsterdam, The Netherlands

5 School of Nursing, Griffith University, Brisbane, Australia

6 Department of Paediatrics and Emergency Medicine, Global Child Health, University of British Columbia, Vancouver, Canada infections [6] or BCG vaccination, will continue to help sustain a relatively lower pandemic impact in Africa remains uncertain. Based on a 2016 ranking index comprising a range of factors including demographics, health care, public health, domestic and international politics, and economics, 22 of the 25 countries considered most vulnerable to infectious disease outbreaks were located in Africa [7]. Thus, strengthening of health systems to prepare for the worst-case scenarios should continue to be an urgent priority.

Current estimates suggest that $80 \%$ of COVID-19 patients have mild infection, while $20 \%$ develop severe illness, among whom 5\% may require critical care to support failure of vital organs [8]. Sepsis, defined as 'lifethreatening organ dysfunction due to a dysregulated host response to infection', is, therefore, a significant manifestation of COVID-19 either caused by the virus or as a result of secondary infection [9]. Favorable outcomes of sepsis patients are associated with the availability of suitably skilled critical care human resources and infrastructure [10]. While data on the number of patients who

7 National Ribat University, Khartoum, Sudan

8 Aminu Kano Teaching Hospital, Kano, Nigeria

9 Faculty of Medicine, University of Khartoum, Khartoum, Sudan

10 Department of Anaesthesia and Surgical Intensive Care Medicine, Charité, Global Sepsis Alliance, Universitätsmedizin Berlin, Berlin, Germany

11 Pulmonology and Critical Care, Charlotte Makeke University Hospital, University of the Witwatersrand, Johannesburg, South Africa

12 Liverpool School of Tropical Medicine, Liverpool, UK 
receive advanced levels of supportive care in Africa are sparse [11], available data suggest that capacity is severely limited [12], with fewer than 2000 functioning ventilators [3] representing 1/650,000 people compared with approximately 1/1,655 in the United States [13]. Ultimately, African countries require resilient and functional health systems that are equipped to safely manage potential surges in patient numbers with staff trained to recognize and respond to severe illness outbreaks with fundamental levels of care (including oxygen) [11], augmented by expertise in critical care for the smaller percentage of patients who might require it.

In 2017, the African Sepsis Alliance published the Kampala Declaration highlighting the need for African countries to strengthen healthcare systems to respond to the needs of patients with severe illness such as sepsis [14]. The recommendations from the Kampala Declaration remain as valid during the COVID-19 pandemic. The COVID-19 pandemic offers an opportunity for countries to implement the Kampala Declaration and strengthen essential services to respond to the current pandemic and outbreaks of future emerging infections. We support the approach taken by most African countries which focuses on improving existing infrastructure rather than erecting temporary 'field hospitals'. Furthermore, recurrent Ebola virus disease outbreaks and the COVID19 epidemic on the continent reinforce the need for effective critical care for improved survival; this resource can no longer be considered a luxury.

We suggest that attention should focus on three key recommendations:

1. Improving systems to identify, monitor and respond to patients with severe illness and reduce time to effective treatment.

2. Improving and enhancing the supply and access to oxygen in many regions, an essential intervention that has the potential to save significant numbers of lives in Africa.

3. Improving COVID-19 infection control measures including preventive measures for healthcare workers.

These objectives can be achieved through national action plans for sepsis that systematically address a country's specific needs for delivering care for severely ill patients. These plans should be developed by national Ministries of Health working with stakeholders such as the Global Sepsis Alliance, African Sepsis Alliance, CDC Africa, African Union and WHO. In so doing, African countries will align with statements in the 2017 WHO sepsis declaration [15]. We submit that this fortification of African health systems will benefit not only patients in the short term but whole populations in the long term.
Author contributions All authors contributed to the conception of this paper. EN wrote the first draft of the paper, with input from the other authors. All authors contributed to, and endorsed the final version of the paper.

Funding None received.

\section{Compliance with ethical standards}

Conflicts of interest None of the authors has any conflict of interest to declare.

\section{References}

1. WHO, WHO Coronavirus Disease (COVID19) Dashboard, [updated 2020 Sep 27; cited 2020 Sep 27]. Available from: https ://covid19.who.int.

2. Africa Centre for Disease Control and Prevention, Africa CDC Dashboard, Available from https://africacdc.org/covid-19/. [Accessed August 10, 2020].

3. WHO (Regional office for Africa), COVID-19 pandemic expands reach in Africa, [updated 2020 Apr 10; cited 2020 Aug 10] Available from https://www.afro.who.int/news/covid-19-pandemicexpands-reach-africa .

4. UN, Office of the Special Adviser on Africa, [cited 2020 Aug 15] Available from https://www.un.org/en/africa/osaa/peace/youth .shtml

5. African Centre for Strategic Studies, Mapping Risk Factors for the Spread of COVID-19 in Africa, [updated 2020 May 13; cited 2020 Aug 10]. Available from https://africacenter.org/spotlight/ mapping-risk-factors-spread-covid-19-africa/.

6. Nordling L. The pandemic appears to have spared Africa so far. Scientists are struggling to explain why, American Association for the Advancement of Science - Science, [updated 2020 Aug 11; cited 2020 Aug 15]. Available from https://www.sciencemag.org/ news/2020/08/pandemic-appears-have-spared-africa-so-far-scien tists-are-struggling-explain-why

7. Moore M, Gelfeld B, Okunogbe A, Paul C. Identifying future disease hot spots: infectious disease vulnerability index, 1 st edn santa monica. California: RAND Corporation; 2016.

8. Centre for Disease Control, Interim Clinical Guidance for Management of Patients with Confirmed Coronavirus Disease (COVID-19) [updated 2020 Sep 10; cited 2020 Sep 27]. Available from https://www.cdc.gov/coronavirus/2019-ncov/hcp/clini cal-guidance-management-patients.html.

9. Langford BJ, So M, Raybardhan S, et al. Bacterial co-infection, and secondary infection in patients with COVID-19: a living rapid review and meta-analysis. Clin Microbiol Infect. 2020 [epub ahead of print]. https://doi.org/10.1016/j.cmi.2020.07.016

10. Devlin JW, O'Neal HR, Thomas C, et al. Strategies to optimize ICU liberation (A to F) bundle performance in critically ill adults with Coronavirus Disease 2019. Crit Care Explor. 2020;2:e0139.

11. Dubbink JH, Branco TM, Kamara KBB, et al. COVID-19 treatment in sub-Saharan Africa: If the best is not available, the available becomes the best. Travel Med Infect Dis. 2020;37:101878. https://doi.org/10.1016/j.tmaid.2020.101878.

12. Wehrens E, Bangura JS, Falama AS. Primum non nocere: Potential indirect adverse effects of COVID-19 containment strategies in the African region. Travel Med Infect Dis. 2020;35:101727. https://doi.org/10.1016/j.tmaid.2020.101727.

13. Halpern NA, Tan KS. United States Resource Availability for COVID-19, Society of Critical Care Medicine, [updated 2020 May 12; cited 2020 Aug 15]. Available from https://sccm.org/ 
Blog/March-2020/United-States-Resource-Availability-forCOVID-19.

14. African Sepsis Alliance, Kampala Declaration: Commitment to improve care for sepsis and critically ill patients in Africa, [updated 2017 Oct 20; cited 2020 Aug 10]. Available from https ://www.africansepsisalliance.org/kampaladeclaration.
15. WHA - Seventieth World Health Assembly. Improving the prevention, diagnosis and clinical management of sepsis, published online May 29, 2017 Available at https://apps.who.int/gb/ebwha /pdf_files/WHA70/A70_R7-en.pdf?ua=1 [Accessed August 15, 2020]. 